\title{
Ex vivo evaluation of intravitreal mesenchymal stromal cell viability using bioluminescence imaging
}

\author{
Carolina Assis P. Vilela ${ }^{1 *}$ D, Lucas Eduardo B. Souza ${ }^{2}$, Rubens C. Siqueira ${ }^{1}$, Rodrigo T. Calado², Dimas T. Covas ${ }^{2}$ \\ and Jayter S. Paula'
}

\begin{abstract}
Background: Bone marrow-derived mesenchymal stromal cell (MSC) therapy is a promising treatment for several degenerative ocular diseases; however, no reproducible method of monitoring these cells into the eye has been established. The aim of this study was to describe successful bioluminescence imaging (BLI) to detect viable luciferase-expressing MSC in the eye.
\end{abstract}

Methods: Human donor MSC in culture were transduced with $50 \mu$ l luciferase lentiviral vector (three viral particles/ cell) prior to intraocular injection. Twenty-one right eyes of 21 rabbits were evaluated through BLI after receiving $1 \times 10^{6}$ luciferase-expressing MSC intravitreally. Contralateral eyes were injected with vehicle (phosphate-buffered saline (PBS)) and were used as controls. At seven different time points (1 h to 60 days), D-luciferin ( $40 \mathrm{mg} / \mathrm{ml}, 300 \mu \mathrm{l}$ PBS) was injected in subsets of six enucleated eyes for evaluation of radiance decay through BLI analysis. CD90 and CD73 immunofluorescence was studied in selected eyes.

Results: Eyes injected with MSC showed high BLI radiance immediately after D-luciferin injection and progressive decay until 60 days. Mean BLI radiance measures from eyes with luciferase-expressing MSC were significantly higher than controls from $8 \mathrm{~h}$ to 30 days. At the thirtieth day, positive CD90- and CD73-expressing cells were observed only in the vitreous cavity of eyes injected with MSC.

Conclusions: Viable MSC were identified in the vitreous cavity 1 month after a single injection. Our results confirmed BLI as a useful and reliable method to detect MSC injected into the eye globe.

Keywords: Bioluminescence, Cell transplantation, Cell viability assessment, Intravitreal injection, Luciferase, Mesenchymal stromal cell

\section{Background}

Mesenchymal stromal cells (MSC) are considered as a specific multipotent population of cells that can be isolated from some tissues including bone marrow. These cells are different to hematopoietic stem cells mainly because they are adherent to dishes and exhibit fibroblast-like colonies in culture, besides being positive for several specific cellular markers $[1,2]$. The use of MSC was initially based on their

\footnotetext{
* Correspondence: carolassisp@yahoo.com.br

'Department of Ophthalmology, Otorhinolaryngology and Head and Neck Surgery, Ribeirão Preto Medical School, University of São Paulo, Av. Bandeirantes, 3900 - 12. Andar, Ribeirão Preto, São Paulo 14049-900, Brazil Full list of author information is available at the end of the article
}

potential differentiation into several tissues; however, an immunomodulatory property has been recently proposed [3].

These findings support the rationale of developing strategies for MSC transplantation as a regenerative therapy, especially in highly specialized organs [2-6]. The in vivo function of MSC probably depends on the pathologic stimuli that each tissue has experienced. In this context, ocular tissues may represent a good target for studying MSC actions since several neuroretinal diseases have different degrees of underlying inflammation associated with a progressive lack of highly specialized cells $[7,8]$.

The major problem related to the use of MSC in the eye, as well as other organs, is the difficulty in assessing cellular survival and activity continuously, which are key

(c) The Author(s). 2018 Open Access This article is distributed under the terms of the Creative Commons Attribution 4.0 International License (http://creativecommons.org/licenses/by/4.0/), which permits unrestricted use, distribution, and 
points for determining the efficacy of treatment and the best MSC transplantation protocols [9-14]. In vivo optical bioluminescence imaging (BLI) is a newly developing technology for dynamically observing the biological behavior of viable cells. BLI allows the detection of light emitted by cells expressing light-generating enzymes [15]. Using this technology, the cells of interest are genetically modified to express luciferase, an enzyme that generates visible light through the oxidation of specific substrates such as D-luciferin [16]. In this study, we demonstrate the feasibility of using BLI to detect intraocular viable luciferase-expressing MSC in an ex vivo rabbit eye model, confirmed by immunofluorescence assays.

\section{Methods}

\section{Isolation of human MSC}

Bone marrow tissues of normal subjects were harvested for allogenic bone marrow transplantation after informed consent according to routine institutional protocols. In the present study, mononuclear cells from a single donor were centrifuged over a Ficoll-Hypaque gradient (Sigma, St. Louis, MO) and plated in $180 \mathrm{~cm}^{2}$ dishes with $10 \mathrm{ml}$ MSC in alpha-minimum essential medium (MEM; Gibco Life Technologies, Burlington, ON, Canada) plus 15\% fetal bovine serum (FBS). The nonadherent cells were removed after 3 days by washing with phosphate-buffered saline (PBS), and monolayers of adherent cells were cultured until confluence. Then, cells were trypsinized (0.025\% trypsin/ $0.1 \%$ EDTA/sodium pyruvate) and plated at 5000 cells/ $\mathrm{mm}^{2}$ density for use at passages 3 to 4 for the experiments.

Passage three MSC were tested with various differentiation media according to the manufacturer's recommendations (Miltenyi Biotec, Auburn, CA) to determine their potential for differentiation. Cellular phenotyping was performed for positivity for CD73, CD90, CD105, and negativity for CD14, CD34, CD45, and HLA-DR expression according to the International Society for Cellular Therapy $[17,18]$.

\section{MSC transduction}

A recombinant lentiviral vector expressing luciferase-2 (Luc2) was incubated with MSC using a three viral particles/cell proportion. Detection and viability of transduced MSC were made using quantitative real-time polymerase chain reaction (qRT-PCR). Detailed steps of the protocol used are described by Kidd et al. [19] and modified locally by Meirelles (unpublished data). In summary, our lentiviral vector is bicistronic and codes for luciferase- 2 and puromycin- $\mathrm{N}$-acetyltransferase, which confers cellular resistance to puromycin. We performed transduction of MSC at the first passage using the mentioned multiplicity of infection (3:1). After $48 \mathrm{~h}$ of transduction, cells were incubated in $2 \mu \mathrm{g} / \mathrm{ml}$ puromycin for 6 days. This treatment leads to $100 \%$ of death in nontransduced MSC (i.e., $100 \%$ of transduced MSC in culture). After puromycin selection, all the isolated transduced MSC were expanded and transplanted at the third passage, as explained previously. The transduced MSC used in this study were kindly provided by the Hemotherapy Center of Ribeirão Preto, Ribeirão Preto Medical School, University of São Paulo.

\section{Ex vivo model of intravitreal injection of MSC}

A preliminary study was performed using three eyes of two New Zealand rabbits (Oryctolagus cuniculus) euthanized with intravenous pentobarbital $(150 \mathrm{mg} / \mathrm{kg})$.

Two eyes (E1 and E2) received an intravitreal single dose of $1 \times 10^{6}$ transduced MSC (300 $\left.\mu \mathrm{l}\right)$ through a pars plana injection using a 30-Gauge needle. To evaluate immediate (using E1) and delayed (using E2) intraocular viability of the transduced MSC, cells were suspended in $300 \mu \mathrm{l}$ PBS with (E1) or without (E2) D-luciferin $(40 \mathrm{mg} / \mathrm{ml})$. A third eye (E3) received a pars plana intraocular injection of D-luciferin $(40 \mathrm{mg} / \mathrm{ml}$ in PBS, $300 \mu \mathrm{l})$ without cells. At $1 \mathrm{~h}$ after the intraocular infusions, E2 received an additional intravitreal injection of D-luciferin $(40 \mathrm{mg} / \mathrm{ml}$ in PBS, $300 \mu \mathrm{l})$ without cells. All eyes underwent a protocol for bioluminescent detection from time zero for $8 \mathrm{~h}$ as further described. This set of experiments was repeated twice and was used to observe how long the MSC would produce luminescence considering the dose of D-luciferin used.

After analyzing the preliminary results, the study was extended until 8 weeks. A one-time intravitreal injection of transduced MSC was then performed in live rabbits to observe the bioluminescent decay curve. Eighteen right eyes of 18 animals received a single 30-Gauge pars plana intravitreal injection of $1 \times 10^{6}$ transduced MSC $(300 \mu \mathrm{l})$ at time point zero. Left eyes received a pars plana injection of $300 \mu \mathrm{l}$ vehicle and served as controls.

At each time point, three animals were euthanized using intravenous pentobarbital $(150 \mathrm{mg} / \mathrm{kg})$ and the eyes were enucleated. Thus, each eye received a pars plana intravitreal injection of D-luciferin $(40 \mathrm{mg} / \mathrm{ml}$ in PBS, $300 \mu \mathrm{l})$ and was used immediately for bioluminescent detection as further described.

All the animals were donated by the Central Bioterium of the University of São Paulo (Ribeirão Preto Campus). The animal procedures were performed in accordance with the ARVO Statement for the Use of Animals in Ophthalmic and Vision Research. We also obtained approval from the Ethics Committee on Animal Experiments of the School of Medicine of Ribeirão Preto, University of São Paulo.

\section{Bioluminescent detection of transduced MSC}

Bioluminescent images were obtained using the IVIS Lumina Imaging System ${ }^{\bullet}$ (Caliper LifeSciences). The authors set the exposure time at $1 \mathrm{~s}$ and the luminescent signal was quantified in the images through the Living Image 
Version 3.0.4 software (Caliper LifeSciences). The obtained signals were presented in photons/seconds $(\mathrm{p} / \mathrm{s})$ in the interest region $\left(\mathrm{cm}^{2}\right)$ in 6-min cycles. For the comparative analyses between the time points, peak values of the luminescent signal results were considered.

\section{Immunofluorescence assays}

At the 30- and 60-day time points, after bioluminescent analyses, all eyes were prepared for routine histology (hematoxylin and eosin (H\&E)) and immunostaining for human CD90 and CD73. Whole globes were fixed in 10\% buffered formalin, embedded in paraffin, and transferred to microscope slides after 6- $\mu \mathrm{m}$ anteroposterior microsectioning (Leica Jung RM2065, Leica Microsystems GmbH, Wetzlar, Germany) and mounted using Tissue Tek $^{\circ}$ Glas $^{\mathrm{Tm}}$ Mounting Media (Sakura Finetek USA).

The immunostaining assays were performed after deparaffinization and rehydration with xylene and descending ethanol series. Then, slices were incubated with the primary antibody anti-CD90 (\#555593, BD Biosciences Pharmingen) and anti-CD73 (\# 550256, BD Biosciences Pharmingen) at 1:200 in 1\% bovine serum albumin (BSA) solution for $2 \mathrm{~h}$ followed by three-times PBS washing, and incubation with the secondary antibody Alexa Fluor 647 (BioLegend, San Diego, CA, USA) at 1:500 for $1 \mathrm{~h}$ at room temperature in darkness. The slides were mounted with ProLong ${ }^{\bullet}$ Gold Antifade Reagent with DAPI (Life Technologies, Carlsbad, CA, USA). The images were obtained using a digital microscope (Leica Microsystems, DFC 310 FX, Wetzlar, Germany). Images of retinal and intravitreal histology and cell immunostaining were compared between eyes that underwent transduced MSC injections and controls. In conducting immunostaining assays we considered the MSC lack of immunogenicity at different sites in addition to the vitreous cavity characteristics of being in an immune-privileged host environment.

\section{Statistical analysis}

Data are presented through descriptive statistics and scattered plot graphs. Comparisons of Log-transformed results of luminescent signals were made using $t$ tests (Prism 6.0, GraphPad software Inc., CA, USA).

\section{Results}

Immediately postinjection, an intraocular luminescent signal from transduced MSC was detected only in E1 (Fig. 1). A Kruskal-Wallis test showed a significant difference between E1, E2, and E3 at the beginning $(p<0.001$; mean \pm standard deviation for E1, E2, and E3 was $2.91 \times 10^{9} \pm$ $9.0 \times 10^{7}, \quad 1.97 \times 10^{8} \pm 2.37 \times 10^{6}$, and $1.18 \times 10^{8} \pm 1.94 \times$ $10^{6}$, respectively; Fig. 2). After intravitreal injection of D-luciferin in E2, an immediate peak of luminescence was observed $\left(7.50 \times 10^{9}\right)$, with decay to the E1 levels over a 1.5-h period. E2 maintained the plateau levels of E1 luminescent until $8.0 \mathrm{~h}$, with no observed changes in the background levels of E3 (Figs. 1 and 2).

A significant decreasing detection of the luminescent signal was observed at $8 \mathrm{~h}$ and 1, 2, 10 and 30 days after the intravitreal injection of transduced MSC $(p<0.05)$. At 60 days after injection, the luminescent levels were similar to the control eyes (Fig. 2).

Histological evaluation at day 30 showed cells located exclusively in the vitreous cavity of eyes injected with transduced MSC, which could be described as lymphomononuclear cells based on their morphological characteristics. No cells were found in any other ocular structures. Virtually all cells displayed in the vitreous cavity were both CD73 and CD90 positive (Figs. 3 and 4), and no cells were detected in the vitreous cavity of all eyes at day 60 .

\section{Discussion}

Stem cell-based therapies have rapidly emerged as potential therapeutic approaches for several pathologic conditions. Their multiplicity of potential action has been evaluated in several diseases since MSC may present various properties, including transdifferentiation into several cells types and modulation of the microenvironment [2024]. In fact, their paracrine effect is potentially related to the modulation of the activity of immune cells, including inhibition of B cell and natural killer cell proliferation and neutrophil activation, which would be mediated by several secreted factors [25-28]. Although these effects could be beneficial for different eye conditions, including retinal vascular disease and glaucoma [29-33], a recent study has reported severe ocular complications using intravitreal adipose tissue-derived MSC to treat patients with age-related macular degeneration [34].

Reliable markers to track MSC viability in vivo are needed, mainly in terms of cell tracking in the organs where cells are transplanted, especially into the eye. Several recent studies have reported the use of stem cells to treat ocular pathologic conditions [35-39].

Unlike end-point studies, BLI provides real-time, noninvasive assessment of in situ events, giving a better understanding of the kinetics of a biological process at multiple time points with the use of less animals. In this study, we demonstrated the viability of luciferase-expressing MSC injected intravitreally in a significant amount up to 30 days after injection. This is a new interesting advance regarding monitoring living cells. Previous reports have shown their beneficial effects in several ocular conditions; however, they have failed to show the maintenance of living transplanted cells in the eye [40]. Shi et al. [41] showed the presence of endothelial progenitor cells labeled with several concentrations of 5- (and 6)-carboxyfluorescein diacetate succinimidyl ester (CFSE) in laser-injured mouse retina using angiography. Similar to our results, they 

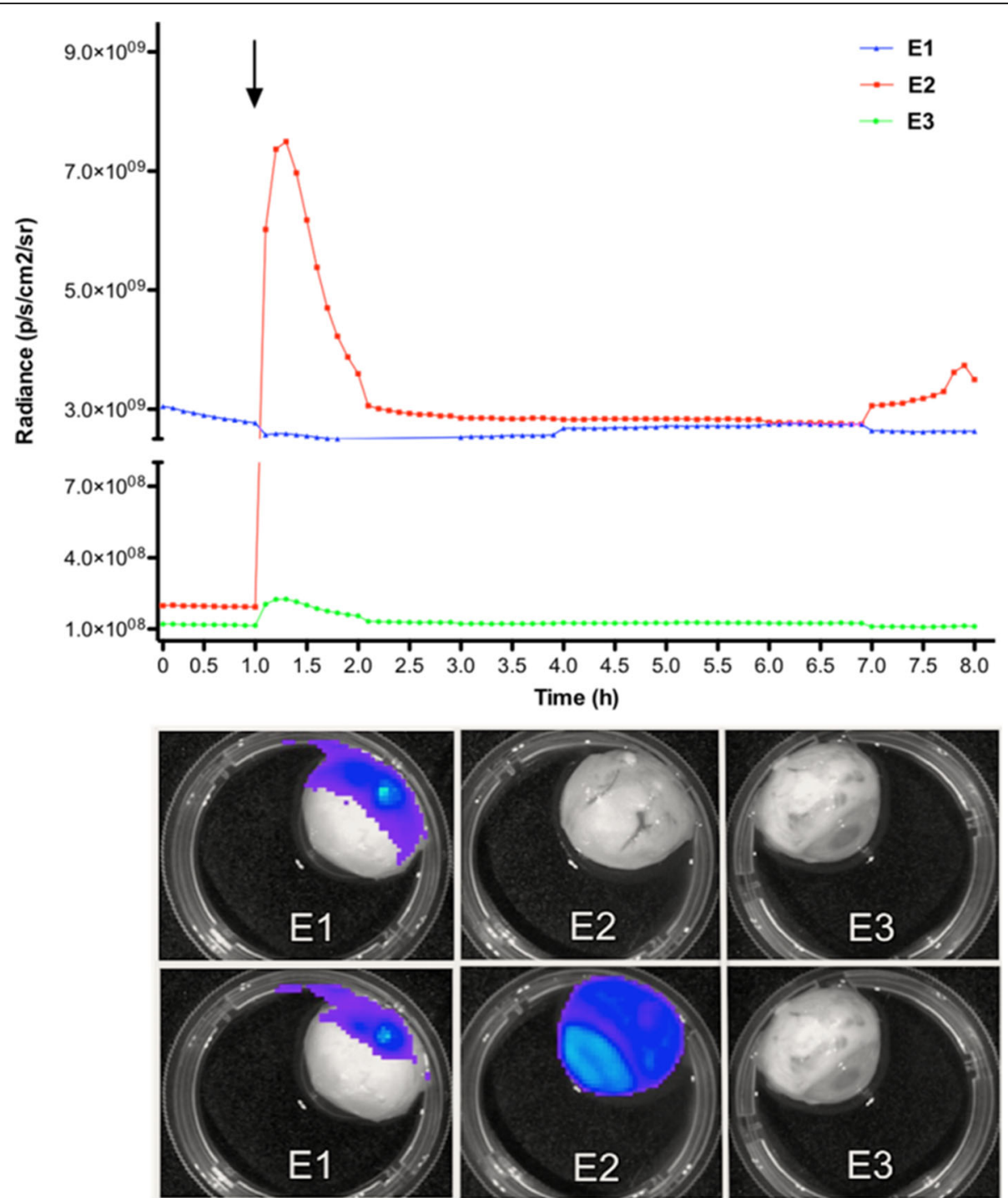

Fig. 1 Bioluminescence results obtained from the three experimental eyes in the preliminary study. Top panel shows the distribution of the total amount of captured photons/second from the three eyes during the 8-h period. Bioluminescent levels were obtained from E1 (MSC + D-luciferin (40 mg/ml, $300 \mu \mathrm{l})$, E2 (MSC before and after injection of D-luciferin (40 mg/ml, $300 \mu l)$ ); black arrow), and E3 (D-luciferin (40 mg/ml, $300 \mu l)$ ). Bottom panel shows bioluminescence imaging acquired at $t=0 \mathrm{~h}$ (first row) and $t=1.5 \mathrm{~h}$ (second row) after the additional injection of $\mathrm{D}-\mathrm{luciferin}$ (40 $\mathrm{mg} / \mathrm{ml}$, $300 \mu$ l) performed in E2

described decreases in the fluorescence intensity at the end of 4 weeks. Notwithstanding, BLI has been used for imaging MSC injected into the myocardium, kidney, and subcutaneous scaffolds [42-46]. This widespread use of BLI shows its reproducibility as a method for tracking injected MSC, and highlights the importance of testing BLI protocols for a time-course evaluation of intraocular MSC.

In the preliminary tests, as expected, D-luciferin applied together or after luciferase-expressing MSC provided reliable luminescent observations, reaching the same ranges. Nevertheless, we observed a rapid peak of luminescent when D-luciferin was injected after transfected cells have been injected (E2). The luminescence reached higher levels than those presented when D-luciferin and cells were injected together (E1). The explanation for this observation could be based on the increased enzymatic activity of cells in E2 before receiving D-luciferin, which would lead to higher photon flux; however, this explanation is open to debate.

The luminescent signal decay during the experimental time points ( $8 \mathrm{~h}$ until 60 days) could be attributed to losses of viable MSC. Shi et al. [41] have also reported the decrease in fluorescence intensity during the extended culture period as well as in an in vivo model.

The clinical interest regarding safety and efficacy of using human MSC, as well as ethical limitations and its potential further applications for treating eye disorders, justifies our 


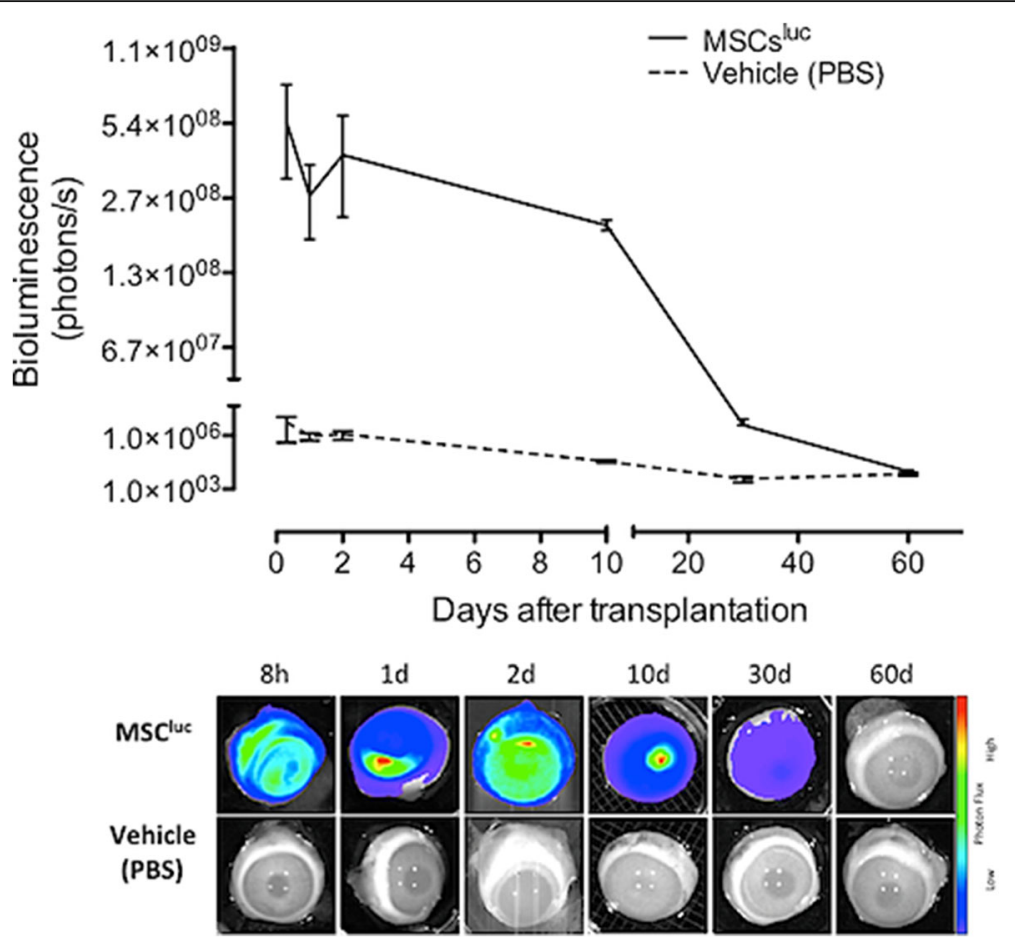

Fig. 2 Bioluminescence results during the 60 days of follow-up. Top panel shows the distribution of the total amount of captured photons/second at six time points during the 60 days after the intravitreal injection of transduced mesenchymal stromal cells (MSC) in rabbit eyes (solid line) compared with controls (phosphate-buffered saline (PBS); dashed line). Mean \pm standard error (error bars) of bioluminescent levels were obtained from triplicates of eyes at each time point (methodological details are presented in the main text). All readings (from $8 \mathrm{~h}$ to 30 days), apart from those at day 60 , were significantly higher than controls. Bottom panel shows examples of bioluminescence imaging acquired from eyes injected with transduced MSC (MSCluc; first row) or controls (vehicle/PBS; second row)

proposal for the xenograft ex vivo rabbit model. Furthermore, based on the lack of signs of any ocular inflammation, such as vitritis or retinitis, the present model may be used in future studies on stem cell treatment of eye diseases since MSC usually present with low immunogenicity, and the vitreous cavity may work as an immune-privileged host environment. Besides, the immunofluorescence assays were performed to confirm our bioluminescence results regarding the presence of MSC into the vitreous cavity. At day 30, virtually all intravitreal cells retained their immunophenotype because of both human CD73 and CD90 positivity, indicating these as the injected MSC. Comparing the global

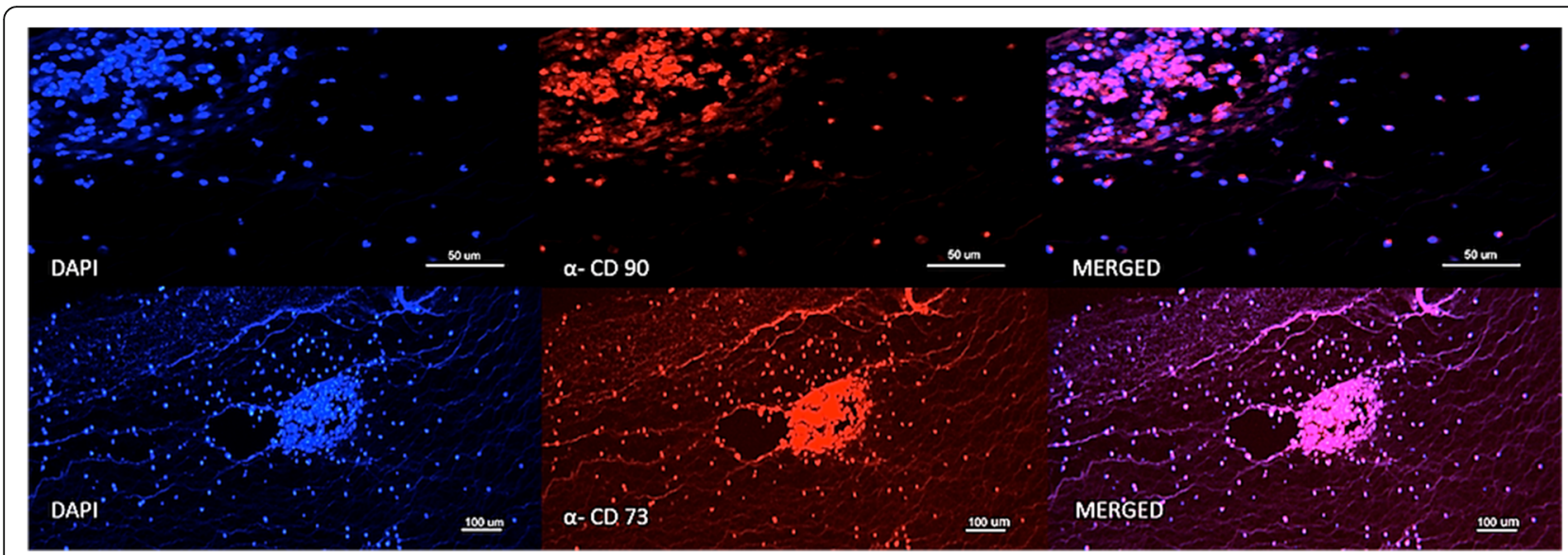

Fig. 3 Immunofluorescence expression of cells located into the vitreous cavity of eyes harvested at day 30 after the intravitreal injection of transduced MSC. Top panels: anti-CD90 counterstained with DAPI; bottom panels: anti-CD73 counterstained with DAPI 


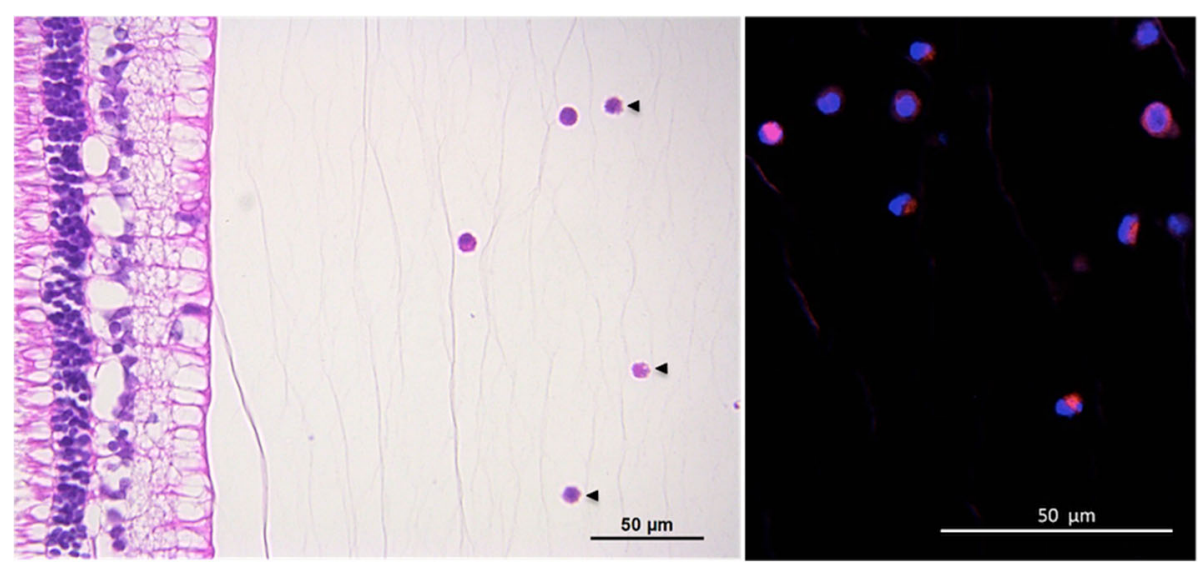

Fig. 4 Photomicrography (left) and immunofluorescence images of cells (right) taken 30 days after the transplantation of the transduced MSC. Note few cells located close, but not attached, to the retina layers (right, H\&E staining; magnification 400X). Some shrinking cells may be observed (arrowheads) indicating cell death at that time. At a higher magnification, the immunofluorescence expression of anti-CD90 could be verified on the surface of some cells in selected microscopic fields of the vitreous cavity (anti-CD90, counterstained with DAPI; magnification 630X)

bioluminescence levels between the time points of $8 \mathrm{~h}$ and 30 days, approximately $0.6 \%$ of the transduced MSC would be alive in the vitreous cavity at day 30. Although MSC could be taken up by phagocytes, we believe that intact enzymes of live cells left over (as observed in Figs. 3 and 4) were able to produce the source of light detected. We did not perform a histological estimation of the number of cells at that time because of the likely biased serial counting associated with potential loss of vitreous material during the preparation of the slices.

Summarizing, the immunofluorescence positivity to human CD73 and CD90 and the observed residual activity of the luciferase indicate a long-lasting, low immunological response to the transduced human MSC in this xenogeneic model. We speculate that either the previously described "immune privilege" of the vitreous or the local immunosuppressive effects of the injected MSC would explain our results. Although our results are straightforward, the use of human MSC from a single donor could be considered a limitation due to a potential heterogeneity of the cell biology.

Thus, the present ex vivo model of rabbit eyes used to evaluate MSC location and viability is a valuable additional tool for monitoring transplanted cells to the eye. Nonetheless, its clinical application in humans has not yet been studied and requires further safety trials. The possibility of repeated D-luciferin injections in the eyes of the rabbits represents an attractive advantage; however, additional evaluations of this method and a more in-depth understanding on phagocytosis processes are necessary to determine long-term dynamics of viable MSC and their mechanisms of action.

\section{Conclusions}

Our ex vivo model using rabbit eyes demonstrated that transplanted viable MSC could be detected in the vitreous cavity 1 month after a single eye injection. These results may confirm BLI as a useful and attractive method to detect modified MSC injected into the eye globe.

\section{Abbreviations \\ BLI: Bioluminescence imaging; MSC: Mesenchymal stromal cells}

\section{Acknowledgements}

We would kindly like to acknowledge Lindolfo da Silva Meirelles, Luciana Arias Fernandez, and Priscilla C. G. Ferreira for technical support in some BLI tests.

Funding

Financial support from CNPq Brazil (401181/2013-8).

\section{Availability of data and materials}

The datasets used and/or analyzed during the current study are available from the corresponding author on reasonable request.

\section{Authors' contributions}

CAPV collected all data and prepared the written material to be evaluated by the other authors. LEBS prepared the cellular samples, supervised the bioluminescence analysis, and collaborated with data interpretation. RCS, RTC, and DTC have been involved in drafting the manuscript and revising it critically for publication, and provided laboratory support. JSP made substantial contribution to the study conception, design, analysis, and interpretation of data, and has been involved with the writing process. JSP also received the grant approval. All authors read and approved the final manuscript.

\section{Ethics approval and consent to participate}

We obtained approval from the Ethics Committee on Animal Experiments of the School of Medicine of Ribeirão Preto, University of São Paulo (protocol number 0029/2014)

\section{Competing interests}

The authors declare that they have no competing interests.

\section{Publisher's Note}

Springer Nature remains neutral with regard to jurisdictional claims in published maps and institutional affiliations.

\section{Author details}

'Department of Ophthalmology, Otorhinolaryngology and Head and Neck Surgery, Ribeirão Preto Medical School, University of São Paulo, Av. Bandeirantes, 3900 - 12. Andar, Ribeirão Preto, São Paulo 14049-900, Brazil. 
${ }^{2}$ Hemotherapy Center of Ribeirão Preto, Ribeirão Preto Medical School, University of São Paulo Ribeirão Preto, São Paulo, Brazil.

\section{Received: 28 February 2018 Revised: 16 May 2018} Accepted: 17 May 2018 Published online: 13 June 2018

\section{References}

1. Zhang L, Peng L, Wu N, Li L. Development of bone marrow mesenchymal stem cell culture in vitro. Chin Med J. 2012;125:1650-5.

2. Siqueira R. Stem cell therapy for retinal diseases: update. Stem Cell Res Ther. 2011;2:1-10

3. Shi $Y$, Zhou L, Tian J, Wang Y. [Transplanting neural stem cells in nerve conduit to promote rats facial nerve regeneration]. Lin Chung Er Bi Yan Hou Tou Jing Wai Ke Za Zhi. Department of Otolaryngology, Eye and ENT Hospital, Fudan University, Shanghai, 200031, China; 2012;26:1040-1042.

4. Figueroa FE, Carrion F, Villanueva S, Khoury M. Mesenchymal stem cell treatment for autoimmune diseases: a critical review. Biol Res. 2012;45:269-77.

5. Joe AW, Gregory-Evans K. Mesenchymal stem cells and potential applications in treating ocular disease. Curr Eye Res. 2010:35:941-52.

6. Miteva K, Van Linthout S, Volk HD, Tschöpe C. Immunomodulatory effects of mesenchymal stromal cells revisited in the context of inflammatory cardiomyopathy. Stem Cells Int. 2013;2013:1-16.

7. Yu J, Deng Z, Shi J, Zhai H, Nie X, Zhuang H, et al. Differentiation of dental pulp stem cells into regular-shaped dentin-pulp complex induced by tooth germ cell conditioned medium. Tissue Eng. 2006;12:3097-105.

8. Chung JK, Park TK, Ohn YH, Park SK, Hong DS. Modulation of retinal wound healing by systemically administered bone marrow-derived mesenchymal stem cells. Korean J Ophthalmol. 2011:25:268-74.

9. $\mathrm{Wu} J \mathrm{H}, \mathrm{Xia} \mathrm{SJ}$. Stem cell-based therapy for erectile dysfunction. Chin Med J. 2011;124:3810-5

10. Sheikh AY, Lin S-A, Cao F, Cao Y, van der Bogt KE a, Chu P, et al. Molecular imaging of bone marrow mononuclear cell homing and engraftment in ischemic myocardium. Stem Cells 2007;25:2677-2684.

11. Castanheira P, Torquetti LT, Magalhãs DRS, Nehemy MB, Goes AM. DAPI diffusion after intravitreal injection of mesenchymal stem cells in the injured retina of rats. Cell Transplant. 2009;18:423-31.

12. Yanai A, Häfeli UO, Metcalfe AL, Soema P, Addo L, Gregory-Evans CY, et al. Focused magnetic stem cell targeting to the retina using superparamagnetic iron oxide nanoparticles. Cell Transplant. 2012;21:1137-48.

13. Lee E-S, Yu S-H, Jang Y-J, Hwang D-Y, Jeon C-J. Transplantation of bone marrow-derived mesenchymal stem cells into the developing mouse eye. Acta Histochem Cytochem. 2011;44:213-21.

14. Wang HC, Brown J, Alayon H, Stuck BE. Transplantation of quantum dot-labelled bone marrow-derived stem cells into the vitreous of mice with laser-induced retinal injury: survival, integration and differentiation. Vis Res. 2010;50:665-73.

15. Wu J. Noninvasive optical imaging of firefly luciferase reporter gene expression in skeletal muscles of living mice. Mol Ther. 2001;4:297-306.

16. Nealson $\mathrm{K}$, Hastings W, review HJWY. Bioluminescence and chemiluminescence. Photochem Photobiol. 1976;23:461-73.

17. Ullah I, Baregundi Subbarao R, Rho G-J. Human mesenchymal stem cells_current trends and future prospective. Biosci Rep. 2015;35:e00191.

18. Dominici M, Le Blanc K, Mueller I, Slaper-Cortenbach I, Marini F, Krause D, et al. Minimal criteria for defining multipotent mesenchymal stromal cells. The International Society for Cellular Therapy position statement. Cytotherapy. 2006:8:315-7

19. Kidd S, Spaeth E, Dembinski JL, Dietrich M, Watson K, Klopp A, et al. Direct evidence of mesenchymal stem cell tropism for tumor and wounding microenvironments using in vivo bioluminescent imaging. Stem Cells. 2009; 27:2614-23.

20. Phinney DG, Prockop DJ. Concise review: mesenchymal stem/multipotent stromal cells: the state of transdifferentiation and modes of tissue repair-current views. Stem Cells. 2007;25:2896-902.

21. Castanheira P, Torquetti L, Nehemy MB, Goes AM. Retinal incorporation and differentiation of mesenchymal stem cells intravitreally injected in the injured retina of rats. Arq Bras Oftalmol. 2008;71:644-50.

22. Gong L, Wu Q, Song B, Lu B, Zhang Y. Differentiation of rat mesenchymal stem cells transplanted into the subretinal space of sodium iodate-injected rats. Clin Experiment Ophthalmol. 2008:36:666-71.

23. Zhang P, Li J, Liu Y, Chen X, Kang Q, Zhao J, et al. Human neural stem cell transplantation attenuates apoptosis and improves neurological functions after cerebral ischemia in rats. Acta Anaesthesiol Scand. 2009;53:1184-91.
24. Siqueira RC, Voltarelli JC, Messias AMV, Jorge R. Possible mechanisms of retinal function recovery with the use of cell therapy with bone marrowderived stem cells. Arq Bras Oftalmol. 2010;73:474-9.

25. Oh JY, Kim MK, Shin MS, Lee HJ, Ko JH, Wee WR, et al. The anti-inflammatory and anti-angiogenic role of mesenchymal stem cells in corneal wound healing following chemical injury. Stem Cells. 2008;26:1047-55.

26. Crisostomo PR, Markel TA, Wang Y, Meldrum DR. Surgically relevant aspects of stem cell paracrine effects. Surgery. 2008;143:577-81.

27. Markel TA, Wang Y, Herrmann JL, Crisostomo PR, Wang M, Novotny NM, et al. VEGF is critical for stem cell-mediated cardioprotection and a crucial paracrine factor for defining the age threshold in adult and neonatal stem cell function. Am J Physiol Heart Circ Physiol. 2008;295:H2308-14.

28. Markel TA, Crisostomo PR, Wang M, Herring CM, Meldrum DR. Activation of individual tumor necrosis factor receptors differentially affects stem cell growth factor and cytokine production. AJP Gastrointest Liver Physiol. 2007; 293:G657-62.

29. Liang $X$, Ding $Y$, Zhang $Y$, Tse HF, Lian Q. Paracrine mechanisms of mesenchymal stem cell-based therapy: current status and perspectives. Cell Transpl. 2014;23:1045-59.

30. Karl MO. The potential of stem cell research for the treatment of neuronal damage in glaucoma. Cell Tissue Res. 2013;353:311-25.

31. Manuquerra-Gagné $R$, Boulos PR, Ammar A, Leblond FA, Krosl G, Pichette $V$, et al. Transplantation of mesenchymal stem cells promotes tissue regeneration in a glaucoma model through laser-induced paracrine factor secretion and progenitor cell recruitment. Stem Cells. 2013;31:1136-48.

32. Johnson TV, Bull ND, Hunt DP, Marina N, Tomarev SI, Martin KR. Neuroprotective effects of intravitreal mesenchymal stem cell transplantation in experimental glaucoma. Investig Ophthalmol Vis Sci. 2010;51:2051-9.

33. Otani A, Dorrell Ml, Kinder K, Moreno SK, Nusinowitz S, Banin E, et al. Rescue of retinal degeneration by intravitreally injected adult bone marrow-derived lineage-negative hematopoietic stem cells. J Clin Invest. 2004;114:765-74.

34. Kuriyan AE, Albini TA, Townsend JH, Rodriguez M, Pandya HK, Leonard RE, et al. Vision loss after intravitreal injection of autologous "stem cells" for AMD. N Engl J Med. 2017:376:1047-53.

35. Siqueira RC, Messias A, Voltarelli JC, Messias K, Arcieri RS, Jorge R. Resolution of macular oedema associated with retinitis pigmentosa after intravitrea use of autologous BM-derived hematopoietic stem cell transplantation. Bone Marrow Transplant. 2012:48:612-3.

36. Siqueira RC, Messias A, Voltarelli JC, Scott IU, Jorge R. Intravitreal injection of autologous bone marrow-derived mononuclear cells for hereditary retinal dystrophy: a phase I trial. Retina. 2011;31:1207-14.

37. Cyranoski D. Stem cells cruise to clinic. Nature. 2013;494:413.

38. Singh MS, Charbel Issa P, Butler R, Martin C, Lipinski DM, Sekaran S, et al. Reversal of end-stage retinal degeneration and restoration of visual function by photoreceptor transplantation. Proc Natl Acad Sci. 2013;110:1101-6.

39. Schwartz SD, Hubschman J-P, Heilwell G, Franco-Cardenas V, Pan CK, Ostrick RM, et al. Embryonic stem cell trials for macular degeneration: a preliminary report. Lancet. 2017;379:713-20.

40. Park SS, Caballero S, Bauer G, Shibata B, Roth A, Fitzgerald PG, et al. Longterm effects of intravitreal injection of GMP-grade bone-marrow-derived CD34 + cells in NOD-SCID mice with acute ischemia-reperfusion injury. Investig Ophthalmol Vis Sci. 2012;53:986-94.

41. Shi H, Yang W, Cui Z-H, Lu C-W, Li X-H, Liang L-L, et al. tracking of CFSElabeled endothelial progenitor cells in laser-injured mouse retina. Chin Med J. 2011;124:751-7.

42. Min JJ, Ahn Y, Moon S, Kim YS, Park JE, Kim SM, et al. In vivo bioluminescence imaging of cord blood derived mesenchymal stem cell transplantation into rat myocardium. AnnNuclMed. 2006:20:165-70.

43. van der Bogt KEA, Sheikh AY, Schrepfer S, Hoyt G, Cao F, Ransohoff KJ, et al. Comparison of different adult stem cell types for treatment of myocardial ischemia. Circulation. 2008;118(Suppl 1):121-9.

44. van der Bogt KEA, Schrepfer S, Yu J, Sheikh AY, Hoyt G, Govaert JA, et al. comparison of transplantation of adipose tissue- and bone marrow- derived mesenchymal stem cells in the infarcted heart. Transplantation. 2009:87:642-52.

45. Togel F, Yang Y, Zhang P, Hu Z, Westenfelder C. Bioluminescence imaging to monitor the in vivo distribution of administered mesenchymal stem cells in acute kidney injury. Am J Physiol Ren Physiol. 2008;295:F315-21.

46. Hwang DW, Jang SJ, Kim YH, Kim HJ, Shim IK, Jeong JM, et al. Real-time in vivo monitoring of viable stem cells implanted on biocompatible scaffolds. Eur J Nucl Med Mol Imaging. 2008;35:1887. 